Belfast

chrisbaraniuk@gmail.com Cite this as: BMJ 2021;372:n421 http://dx.doi.org/10.1136/bmj.n421 Published: 18 February 2021

\section{Covid-19: How the UK vaccine rollout delivered success, so far}

\author{
Chris Baraniuk explains the elements that have made the UK's vaccination programme a front runner \\ globally and describes the hurdles that lie ahead
}

\section{Chris Baraniuk freelance journalist}

It looks like a world beating performance-the United Kingdom has administered more covid-19 vaccine first doses per 100 people (19) than any other nation of comparable population size. ${ }^{1}$

At the time of writing, 12 million people-roughly as many as the entire population of another vaccine front runner, Israel-have received their first dose of either the Pfizer-BioNTech or Oxford-AstraZeneca vaccine. Daily reports indicate that, on some days, more than half a million people have received a dose.

The government seems reasonably well placed to hit its target of giving 15 million people their first dose by mid-February. But the full story of the vaccination programme shows bumps in the road as well as successes.

\section{Head start}

The UK became the first country in the world to approve a covid-19 vaccine for emergency use in early December. But the groundwork was laid nearly a year earlier, when the Department of Health and Social Care reportedly began planning a mass vaccination programme before confirmation of the first covid-19 case in the UK. ${ }^{2}$ Meanwhile, the Oxford University scientists who would go on to develop a vaccine began meeting to discuss it in January 2020, before the World Health Organization (WHO) had even come up with the name covid-19. ${ }^{3}$ They were already working on a prototype vaccine against the coronavirus that causes MERS and reasoned that they would be able to adapt the chimpanzee adenovirus vector they were using to confer protection against SARS-CoV-2.

Just five months later, in June 2020, the UK signed a contract for 100 million doses of the Oxford-AstraZeneca vaccine. ${ }^{4}$ A separate deal securing access to 30 million doses of the Pfizer-BioNTech vaccine was announced the next month. This was increased to 40 million doses in October. 5 "They've got ahead on ordering vaccines and they've got [the doses in hand] to give," says Simon Clarke, associate professor in cellular microbiology at the University of Reading. "It's as simple as that."

Pascal Soriot, chief executive of AstraZeneca, has said that the early orders were a reason why deliveries to the UK have not been held up in the same way as those to the European Union. Batches of vaccine must be made up months in advance, and because cell cultures are used in the manufacturing procedure, the exact yield is unknown until each process is complete. The UK's deal was struck three months before the EU's, so its batches were set in motion earlier and separate to those earmarked for the EU, the yield of which turned out lower. ${ }^{6}$

The UK's hefty vaccine orders were made in part thanks to the 2011 film Contagion. Health secretary Matt Hancock was spooked by the ending of the film, in which countries ravaged by a respiratory disease are left fighting for a limited number of vaccine doses. He insisted on ordering 100 million

Oxford-AstraZeneca doses despite receiving advice to order a mere 30 million.

The UK government's vaccines taskforce, set up by chief scientific adviser Patrick Vallance and led by venture capitalist Kate Bingham, was established to help accelerate the acquisition and distribution of vaccine doses. Bingham's appointment attracted scrutiny because she does not have a background in vaccine development and is married to a Conservative Party minister. Nonetheless, Hancock cited her "excellent track record in the biotech industry" and "vast experience working with drug and therapeutic discoveries" as reasons for appointing her, given her long running business connections to the likes of BioNTech's chief business officer, Sean Marett.

Since May 2020 the taskforce, consisting of experts in science, technology, and logistics, has secured orders from seven different vaccine manufacturers-a total of 400 million doses or enough to vaccinate the entire UK population three times over. In an interview with La Repubblica ${ }^{7}$ Bingham said that her team placed emphasis on sourcing vaccines that could be used as early as 2020. “We weren't choosing vaccines on the basis of being cheap [but on] being effective and available quickly," she said, adding that they favoured Pfizer-BioNTech over Moderna because of the supply chain to European countries (Moderna had prioritised US supplies), knowing that initial stocks would be limited. Still, it was a gamble at a time when no vaccine had been found to be effective against the virus.

“Our actual upfront cost was £9oom [€100om; $\$ 1200 \mathrm{~m}]$... we were willing to write off the upfront money, which was largely for manufacturing, if actually those vaccines failed," Bingham, who has now stepped down from the taskforce, told $L a$ Repubblica.

By the autumn, clinical trial data indicated that both the Pfizer and AstraZeneca vaccines were highly effective at preventing symptomatic disease. Moderna in the US also reported positive results, prompting the UK government to increase its order from five million to 17 million doses. So far, the Medicines and Healthcare Products Regulatory Agency (MHRA) has approved the Pfizer-BioNTech, Oxford-AstraZeneca, 
and Moderna vaccines for use under emergency authorisation in the UK.

\begin{tabular}{lcc}
\hline Table | UK vaccine orders & & \\
Manufacturer & Doses ordered (millions) & Status \\
\hline Pfizer-BioNTech & 40 & Delivery started \\
\hline Oxford University-AstraZeneca & 100 & Delivery started \\
\hline Moderna & 17 & Approved for use. Deliveries due Spring 2021 \\
\hline Novavax & 60 & Clinical trials ongoing \\
\hline Janssen (Johnson \& Johnson) & 30 & Deliveries due second half 2021, pending MHRA approval \\
\hline Sanofi Pasteur-GSK & 60 & Clinical trials ongoing \\
\hline Valneva & 100 & Clinical trials ongoing. Deliveries potentially across 2021 and \\
& & 2022. \\
\hline CureVac & 50 & Phase III trials
\end{tabular}

\section{Rollout}

At 6.31 am on 8 December 2020 in University Hospital in Coventry, 90 year old Margaret Keenan became the first person in the world to receive a covid-19 jab as part of a mass vaccination programme. Just two months later, millions have followed her.

From theatres to sports halls, and even Salisbury Cathedral, large buildings around the UK have been converted into vaccination sites, alongside hospitals and general practices. Eventually, hundreds of high street pharmacies will join the effort. Large and small vaccination sites are needed, says George Kassianos, national immunisation lead at the Royal College of General Practitioners. "As long as the vaccine supply flows freely to the centres, we will vaccinate even more than the prime minister promised," he says.

According to the government, everyone in England now lives within 10 miles of a vaccination centre. A small number of people living in remote, rural areas have access to mobile vaccination units. In total, there are more than 1400 vaccination sites in England, 1100 in Scotland, 295 in Wales, and 328 in Northern Ireland.

The schedule of priority groups, defining the order in which members of the public should receive the vaccine, was devised by the government's Joint Committee on Vaccination and

Immunisation, made up of scientists, doctors, and others. In line with WHO guidance, first up are care home residents and health workers, then older and clinically extremely vulnerable people. Among those excluded from the mass vaccination plan at present are pregnant women, children under 16 , and those with health conditions that put them at very high risk of serious outcomes. All eligible UK adults are due to be offered a vaccine by the autumn.

Different parts of the UK are approaching the priority group cohorts in roughly the same way, with GPs focusing on older patients and hospitals acting as hubs for the vaccination of health workers. But there are some regional differences. Northern Ireland, for example, launched a twin track approach in January, where seven regional vaccination centres (a mix of hospitals and leisure centres) have offered appointments, bookable online or by telephone, to 65-69 year olds. Some people have received their first dose within 24 hours of booking, though many have reported technical glitches with the online system for requesting an appointment. Meanwhile, GPs continue to offer jabs separately to older and clinically extremely vulnerable people.

The twin track scheme was unveiled suddenly and has befuddled some patients. "We received last minute communication about it," says Louise Douglas, a GP in Belfast. "People have been phoning us saying, 'We can't get an appointment' or, 'We don't want to go to the vaccination centre, we want to come to you." The BMJ has also heard reports of patients in England left confused after they received requests from both their local GP practice and the separate mass vaccination team to come for vaccination. While noting good progress overall, Douglas expresses frustration over being "drip fed" inconsistent and often relatively small batches of doses. "We're only being given 100 at a time," she said. "Unfortunately, that means that we cannot communicate in advance to our patients."

A week after speaking to The BMJ, Douglas's clinic received enough to vaccinate 550 people in one day. Ollie Hart, a GP in Sheffield, says that the first delivery of vaccine doses his practice received was double the number he and colleagues expected-nearly 400 in total. "It was literally the day before, we found that out," he says. He adds that his practice could, in principle, routinely administer hundreds more vaccines per week than at present, were the supplies available and their delivery clearly communicated in advance.

An NHS spokesperson told The BMJ, "Vaccines delivered to the NHS are sent out as soon as possible to vaccination sites, with as much notice given of delivery dates as possible, as supplies come online and are made available to the NHS."

There are measurable disparities in the density of vaccine doses administered so far. Officials have sought to smooth things out, though not without controversy. Doses were redirected from Yorkshire and the north east of England because those areas had vaccinated a higher proportion of their over 80 cohort than parts of southern England. ${ }^{8}$ Hart, whose practice is in Yorkshire, says it is "normal" to see disparities in the rate of vaccination between different parts of the country. "This obsession with keeping everybody absolutely level does seem a little bit strange," he adds.

Still, there are challenges in comprehensively vaccinating every community. Some black and ethnic minority groups are more hesitant about getting vaccinated, in part because of concerns over whether ingredients in jabs are compatible with their religious or cultural beliefs. Nadra Ahmed, the executive chairman of the National Care Association, says that this is one reason why some staff at care home organisations have still not been vaccinated.

\section{Production}

Neither AstraZeneca nor Pfizer has made known the number of doses supplied to the UK so far, though Pfizer told Sky News in early January that 21 shipments had been delivered. ${ }^{9}$ When asked by The $B M J$, a spokesperson declined to give the latest figure of shipments made or clarify how many doses were contained in each shipment. 
AstraZeneca did not respond to requests for comment on the progress of its deliveries.

AstraZeneca's facilities in the UK are producing doses for the country, and the Telegraph reported in January that a new factory in Oxfordshire will be capable of making 70 million doses in 4-5 months, after it opens later this year. ${ }^{10}$ Construction of the Vaccines Manufacturing and Innovation Centre was already underway with a planned 2022 opening, but the government invested an additional f131m to bring the completion forward to $2021 .^{11}$

Doses arriving from production facilities in Europe have, according to the transport secretary, Grant Shapps, continued to move smoothly despite Brexit and French traffic controls. Martin Sawer, executive director of the Healthcare Distribution Association, told The $B M J$ that after vaccine batches are tested by the MHRA - generally taking two days - they are then taken from central storage hubs to vaccination sites by private couriers. Only a small number of companies are handling the Pfizer-BioNTech vaccine, as it requires cold storage at around $-80^{\circ} \mathrm{C}$. "Obviously the whole process is new," says Sawer, adding that the number of staff involved in vaccine deliveries currently number a few hundred. "From my members' point of view, it's going very smoothly."

Sawer says that delivery staff in Northern Ireland have been offered vaccines, but not yet those working elsewhere in the UK. "They're now included as frontline healthcare workers in a way they're not in England, Scotland, and Wales," he says, adding that he would like to see the policy replicated across all four nations.

\section{New challenges}

Even if the government meets its mid-February target, there will still be tens of millions of people waiting in line for their first dose in the coming months. And the challenge will become more complex as vaccinators are tasked with administering millions of second doses on schedule.

With more countries around the world ramping up their own vaccination programmes, wrangling over vaccine supplies has become heated. The UK's much debated decision to delay administrating the second dose from 3 weeks to up to 12 weeks will help stretch vaccine stocks over a larger proportion of the population, with preliminary data for the Oxford-AstraZeneca vaccine indicating that the tactic should allow people to achieve a degree of immunity against the virus while also potentially cutting transmission. ${ }^{12}$ Clarke argues, however, that there are insufficient data to support delayed dosing of the Pfizer-BioNTech vaccine.

And then there is the threat of new variants that could evade immunity, potentially requiring the production and rollout of a new generation of covid-19 vaccines or boosters. Scientists are already working on this, with Oxford University saying that a tweaked version of its vaccine could be available by the autumn..$^{13}$ The government's vaccine taskforce has also struck a deal with German company CureVac to develop new vaccines against emerging covid-19 variants, agreeing to purchase 50 million doses should they prove effective, and to convert an animal vaccine plant to bring human mRNA vaccine production to the UK. To date, the UK has had to rely on overseas production for these vaccines.

The government is already planning for a third round of booster shots in the autumn. And Bingham has spoken of the need for alternative delivery methods to injections, such as nasal sprays or patches, to allow vaccination in pharmacies or even self-administration at home. This could reduce the pressure on hospitals, vaccination centres, and GPs. As we learn to live with the virus and its variants, covid-19 vaccination might become an annual event like flu jobs.

There is much uncertainty ahead. But swift progress of the mass vaccination programme so far has buoyed a country still in its third national lockdown that recently recorded its 100 oooth covid-19 death. "Everybody has come together to deliver," says Kassianos. "That, actually, is our NHS."

Provenance and peer review: Commissioned; not externally peer reviewed.

Competing interests: I have read and understood BMJ policy on declaration of interests and have no relevant interests to declare.

Our World in Data. UK: covid-19 vaccination doses administered per 100 people. https://ourworldindata.org/grapher/uk-covid-vaccination-doses-per-capita?tab=chart\&stackMode=absolute\&time=2021-01-03.latest\&region=World

2 Manthorpe R. Covid-19: rejected contracts and a Hollywood movie-how UK struck deal to guarantee vaccine supply. Sky News 1 Feb 2021. https://news.sky.com/story/covid-19-rejectedcontracts-and-a-hollywood-movie-how-uk-struck-deal-to-guarantee-vaccine-supply-12204044 Boffey D, Sabbagh D. "We had to go it alone": how the UK got ahead in the covid vaccine race. Guardian29 Jan 2021. https://www.theguardian.com/society/2021/jan/29/we-had-to-go-it-alonehow-the-uk-got-ahead-in-the-covid-vaccine-race

4 Lem P. AstraZeneca boss says faster UK vaccines due to contract terms. Research Professional. 27 Jan 2021. https://www.researchprofessionalnews.com/rr-news-europe-innovation-2021-1astrazeneca-boss-says-faster-uk-vaccines-due-to-contract-terms/

5 Pfizer and BioNTech achieve first authorization in the world for a vaccine to combat covid-19. Pfizer. 2 Dec 2020. https://www. pfizer.com/news/press-release/press-release-detail/pfizer-andbiontech-achieve-first-authorization-world

6 Guerrera A, Bolzen B, de Miguel R. Pascal Soriot: "There are a lot of emotions on vaccines in EU. But it's complicated." La Repubblica 26 Jan 2021. https://www.repubbli-

ca.it/cronaca/2021/01/26/news/interview_pascaL_soriot_ceo_astrazeneca_coronavirus_covid_vaccines-284349628/

7 Bolzen S, Guerrera A. Kate Bingham: Why the UK strategy on covid vaccines has been a great success. La Repubblica 6 Feb 2021. https://www.repubbli-

ca.it/cronaca/2021/02/07/news/kate_bingham_interview_vaccines_covid_astrazeneca_uk_coronavirus_johnson-286384093/

8 Dickinson K. NHS England's top GP confirms vaccines are being diverted away from North East. Chronicle Live22 Jan 2021. https://www.chroniclelive.co.uk/news/north-east-news/nhs-englandstop-gp-confirms-19677974

9 Covid-19: No shortages of coronavirus vaccine in UK, says Pfizer. Sky News 2 Jan 2021. https://news.sky.com/story/covid-19-two-million-vaccine-doses-to-be-supplied-each-week-frommid-january-report-12177151

10 Gardner B. Britain will be able to vaccinate nation against new covid strains within months after new super-factory opens. Telegraph 16 Jan 2021. https://www.telegraph.co.uk/news/2021/01/16/britain-will-able-vaccinate-nation-against-new-covid-strains/

11 Department for Business, Energy, and Industrial Strategy, UK Research and Innovation, Sharma A. Vaccines Manufacturing and Innovation Centre to open 12 months ahead of schedule. 17 May 2020. https:/www.gov.uk/government/news/vaccines-manufacturing-and-innovation-centreto-open-12-months-ahead-of-schedule

12 Wise J. Covid-19: New data on Oxford AstraZeneca vaccine backs 12 week dosing interval. BMJ 2021;372:n326. doi: 10.1136/bmj.n326 pmid: 33536232

13 Triggle N, Roxby P. Covid: New Oxford vaccine "ready by the autumn" to tackle mutations. BBC News 5 Feb 2021. https://www.bbc.co.uk/news/health-55917793

This article is made freely available for use in accordance with BMJ's website terms and conditions for the duration of the covid-19 pandemic or until otherwise determined by BMJ. You may use, download and print the article for any lawful, non-commercial purpose (including text and data mining) provided that all copyright notices and trade marks are retained. 